\title{
Seasonal effects on sexual maturation of male bank voles (Clethrionomys glareolus)
}

\author{
M. Kruczek \\ Department of Genetics and Evolution, Institute of Zoology, Jagiellonian University, Kraków, \\ Poland
}

\begin{abstract}
Summary. The weights of the testes and accessory glands, and the degree of morphological and functional development of the seminiferous tubules, were used as indicators of sexual maturation in male bank voles. Males reared under constant laboratory conditions showed a significant relationship between the seasons and sexual maturation. Young males reached maturity most rapidly in the reproduction season (mid-April to mid-October), while adult males matured earlier, in the spring season (mid-January to mid-April). The influence of season on animals reared in outdoor cages was much more pronounced. One of the important factors was the photoperiod: animals reared from 3 to 12 weeks of age in a short photoperiod $(8 \mathrm{~L}: 16 \mathrm{D})$ matured less rapidly than did those reared in $16 \mathrm{~L}: 8 \mathrm{D}$.
\end{abstract}

\section{Introduction}

Under natural conditions, the bank vole (Clethrionomys glareolus) like other microtids, reproduces in spring and summer (Zejda, 1962; Coutts \& Rowlands, 1969). Bank voles reared under constant laboratory conditions with a long photoperiod are capable of reproducing throughout the year (Buchalczyk, 1970; Alder, 1972), although a slight decrease in the number and size of litters is observed (unpublished data). Seasonality of reproduction in wild populations of microtines is determined by climatic conditions and diet. The most important factor seems to be the long photoperiod (for review, see Clarke, 1981), although in some species, e.g. the California vole (Microtus californicus), water and fresh green food are stimulating factors for gonadal and accessory gland growth (Nelson, Dark \& Zucker, 1983).

The mechanisms controlling the sexual maturation of bank vole males are unknown. The present investigation was undertaken to study the influence of the internal biological rhythm, photoperiod and external climatic conditions on sexual maturation in bank vole males.

\section{Materials and Methods}

The animals used in the experiments were obtained from the Mammals Research Institute, Polish Academy of Sciences, Bialowieża, in 1976 and bred in our laboratory as an outbred colony. The animals were reared in mixed sex litters (2-5 young) until weaning at 21 days of age. Afterwards, the juvenile males were kept in groups of 4 per cage. Food and water was provided in excess once daily and consisted of seeds of wheat and oats, red beet and apples.

The males were weighed after death and the gonads and seminal vesicles and coagulating glands were dissected out and weighed (the accessory glands were weighed jointly). The left testis was fixed in Carnoy's solution, embedded in paraffin wax, sectioned at $7 \mu \mathrm{m}$, stained with Delafield's haematoxylin and eosin and classified for functional state using the spermatogenic index (Grocock $\&$ Clarke, 1974). The spermatogenic index (values from 5 to 0 ) gives a measure of seminiferous 
epithelium activity, 5 representing complete spermatogenesis with abundant sperm production and 0 the presence only of Sertoli cells and spermatogonia. The spermatogenic index was determined on 20 seminiferous tubules situated in the centre of testicular cross-sections. The widths of the same 20 seminiferous tubules from each animal were measured.

Three seasons were distinguished as follows. The spring season (Season S) lasted from midJanuary to mid-April and out of doors the season is characterized by an abrupt increase in daylength and the start of rodent reproduction. Season $\mathbf{R}$ was the reproduction season, lasting from mid-April to mid-October, closely corresponding to the reproduction period in wild populations of voles. The winter season (Season W) lasted from mid-October to mid-January and was characterized by rapid shortening of the daylength and the lack of breeding in wild rodents.

Experiment 1. The animals were reared indoors, exposed to a photoperiod of $14 \mathrm{~h}$ light: $10 \mathrm{~h}$ dark (14L:10D) (lights on $08: 00 \mathrm{~h}$ ) and a temperature of $18-20^{\circ} \mathrm{C}$. The investigations were carried out on 3-, 4-, 6- and 12-week-old males born and reared during only one of Seasons S, R or W.

Experiment 2. Males were reared from birth to 12 weeks of age in outdoor cages. Because of the inhibited reproduction in the winter season and at the beginning of spring the studies were limited to the reproduction and winter seasons ( $R$ and $W$ ). The winter-season animals were born by the end of the reproduction period, but the other males were born and matured in Season $\mathbf{R}$.

Experiment 3. After weaning, 3-week-old males were reared to 12 weeks of age under laboratory conditions (temp. $18-20^{\circ} \mathrm{C}$ ) with a short (8L:16D) or long photoperiod (16L:8D). Light intensity was 50 lux. The experiments were carried out throughout the whole year.

Data were analysed by a single-factor analysis of variance (ANOVA) followed by, when indicated, Duncan's multiple range test.

\section{Results}

\section{Experiment 1}

Seasonal changes were found in the body weight in all the age groups investigated (Table 1). The 3-week-old males born in Season W had lighter testes than did those born in Seasons $\mathbf{S}$ and $\mathrm{R}$, but the gonads of 4- and 6-week-old males were lighter in voles born in Seasons W and $S$ than in those born in Season $\mathbf{R}$ (Table 1). In 12-week-old males smaller testes occurred in Season $\mathbf{W}$ (Table 1).

In the males of all age groups (Table 1) the weights of the seminal vesicles and coagulating glands were lower in males born in Season W than those born in Season R.

In the males of all age groups, the highest spermatogenic index (SI) was found in the bank voles born in Season R (Fig. 1). In the 3-week-old males spermatogenesis reached only the stage of primary spermatocytes $(\mathrm{SI}=1)$. In the seminiferous tubules of 4-week-old males born in Seasons $S$ and $R$, elongated spermatids had already appeared $(\mathrm{SI}=3)$. For the first time, mature spermatozoa $(\mathrm{SI}=4)$ were observed in the seminiferous tubules of 6-week-old males born in Seasons $\mathrm{S}$ and $\mathrm{R}$. Complete spermatogenesis $(\mathrm{SI}=5)$ was found only in 12-week-old voles born in all three seasons, but most advanced spermatogenesis was found in those born in Season $\mathrm{R}$.

The diameters of seminiferous tubules of the testes of 3-, 4-, 6- and 12-week-old males (Fig. 2) maturing in winter (Season W) were smaller than those of males born in Seasons $\mathbf{S}$ and $\mathbf{R}$.

\section{Experiment 2}

There was no difference in body weight between the two seasons $(20.6 \pm 0.6 \mathrm{~g}, \mathrm{~N}=9$, for Season $R$ and $19.4 \pm 0.9 \mathrm{~g}, \mathrm{~N}=9$, for Season $\mathrm{W}$ ). Growth of the testes as well as of seminal vesicles and coagulating glands was inhibited in males from Season W (Fig. 3). The seminiferous 
Table 1. Weights of body, testis and accessory glands in 3-, 4-, 6- and 12-week-old bank vole males reared in laboratory conditions (14L:10D) in the spring (Season S), reproduction (Season $\mathbf{R}$ ) or winter (Season W) season

\begin{tabular}{lcccc}
\hline & $\begin{array}{c}\text { No. of } \\
\text { voles }\end{array}$ & $\begin{array}{c}\text { Body } \\
\text { wt }(\mathrm{g})\end{array}$ & $\begin{array}{c}\text { Testes } \\
\text { Wt }(\mathrm{mg})\end{array}$ & $\begin{array}{c}\text { Wt of } \\
\text { seminal vesicles } \\
\text { coagulating glands } \\
(\mathrm{mg})\end{array}$ \\
Season & & & & \\
\hline 3-week-old voles & 10 & $9 \cdot 1 \pm 0 \cdot 3^{\mathrm{a}}$ & $42 \cdot 3 \pm 6 \cdot 6^{\mathrm{d}}$ & $2 \cdot 4 \pm 0 \cdot 0^{\mathrm{a}, \mathrm{b}}$ \\
S & 9 & $9 \cdot 8 \pm 0 \cdot 2^{\mathrm{b}}$ & $49 \cdot 6 \pm 3 \cdot 8^{\mathrm{a}}$ & $2 \cdot 8 \pm 0 \cdot 1^{\mathrm{b}, \mathrm{c}}$ \\
R & 10 & $7 \cdot 6 \pm 0 \cdot 4^{\mathrm{a}, \mathrm{b}}$ & $26 \cdot 8 \pm 1 \cdot 9^{\mathrm{a}, \mathrm{d}}$ & $1 \cdot 9 \pm 0 \cdot 1^{\mathrm{a}, \mathrm{c}}$ \\
W & & & & \\
\hline 4-week-old voles & 9 & $10 \cdot 5 \pm 0 \cdot 5^{\mathrm{a}}$ & $64 \cdot 6 \pm 17 \cdot 0^{\mathrm{d}}$ & $3 \cdot 1 \pm 0 \cdot 5$ \\
S & 10 & $12 \cdot 5 \pm 0 \cdot 5^{\mathrm{a}, \mathrm{b}}$ & $112 \cdot 1 \pm 16 \cdot 2^{\mathrm{a}, \mathrm{d}}$ & $3 \cdot 9 \pm 0 \cdot 5^{\mathrm{a}}$ \\
R & 10 & $10 \cdot 4 \pm 0 \cdot 2^{\mathrm{b}}$ & $51 \cdot 3 \pm 7 \cdot 3^{\mathrm{a}}$ & $2 \cdot 3 \pm 0 \cdot 1^{\mathrm{a}}$ \\
W & & & & \\
\hline 6-week-old voles & 9 & $14 \cdot 4 \pm 0 \cdot 5$ & $224 \cdot 4 \pm 28 \cdot 5^{\mathrm{a}, \mathrm{d}}$ & $21 \cdot 8 \pm 8 \cdot 5$ \\
S & 10 & $14 \cdot 3 \pm 0 \cdot 5$ & $315 \cdot 6 \pm 26 \cdot 8^{\mathrm{b}, \mathrm{d}}$ & $42 \cdot 4 \pm 9 \cdot 8^{\mathrm{a}}$ \\
R & 10 & $13 \cdot 7 \pm 0 \cdot 4$ & $108 \cdot 3 \pm 14 \cdot 3^{\mathrm{a}, \mathrm{b}}$ & $3 \cdot 7 \pm 0 \cdot 6^{\mathrm{a}}$ \\
W & & & & \\
\hline 12-week-old voles & 10 & $20 \cdot 3 \pm 0 \cdot 9^{\mathrm{a}}$ & $680 \cdot 0 \pm 46 \cdot 0^{\mathrm{a}}$ & $261 \cdot 8 \pm 19 \cdot 0^{\mathrm{a}}$ \\
S & 10 & $18 \cdot 5 \pm 0 \cdot 5$ & $630 \cdot 7 \pm 28 \cdot 1^{\mathrm{b}}$ & $268 \cdot 2 \pm 3 \cdot 1^{\mathrm{b}}$ \\
R & 10 & $17 \cdot 1 \pm 0 \cdot 4^{\mathrm{a}}$ & $426 \cdot 8 \pm 38 \cdot 9^{\mathrm{a}, \mathrm{b}}$ & $133 \cdot 8 \pm 25 \cdot 4^{\mathrm{a}, \mathrm{b}}$ \\
W & & &
\end{tabular}

Values are mean \pm s.e.m.

a, b, c, $P<0.01 ; \mathrm{d}, P<0.05$.

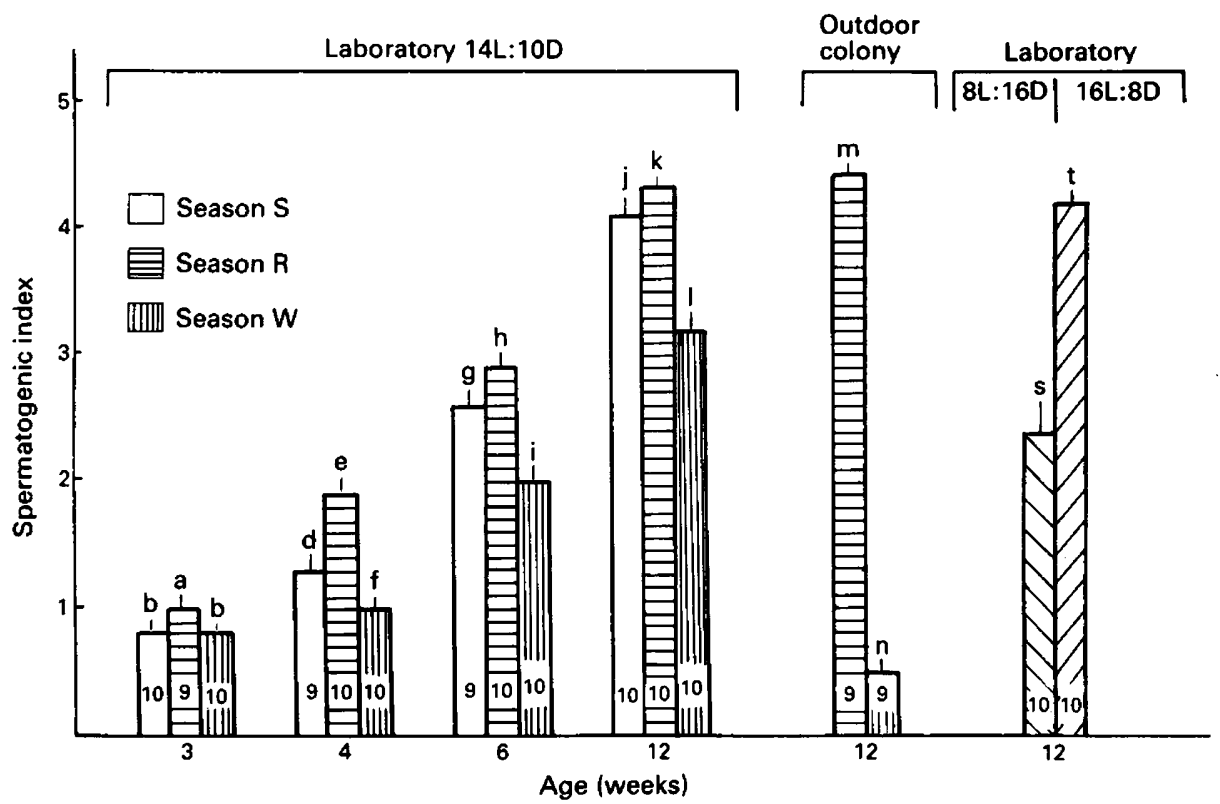

Fig. 1. Spermatogenic index (SI) of bank voles reared in various conditions in Exps 1,2 and 3. Values are mean \pm s.e.m. for the sample size indicated. a $v s \mathrm{~b}, \mathrm{~d} v s \mathrm{e}, \mathrm{d} v s \mathrm{f}, \mathrm{e} v s \mathrm{f}, \mathrm{g} v s \mathrm{~h}, \mathrm{~g} v s \mathrm{i}$, $\mathrm{h} v s \mathrm{i}, \mathrm{j} v s \mathrm{k}, \mathrm{j} v s \mathrm{l}, \mathrm{k} v s \mathrm{l}, \mathrm{m} v s \mathrm{n}, \mathrm{l} v s \mathrm{n}, \mathrm{s} v s \mathrm{t}, P<0 \cdot 01$. 


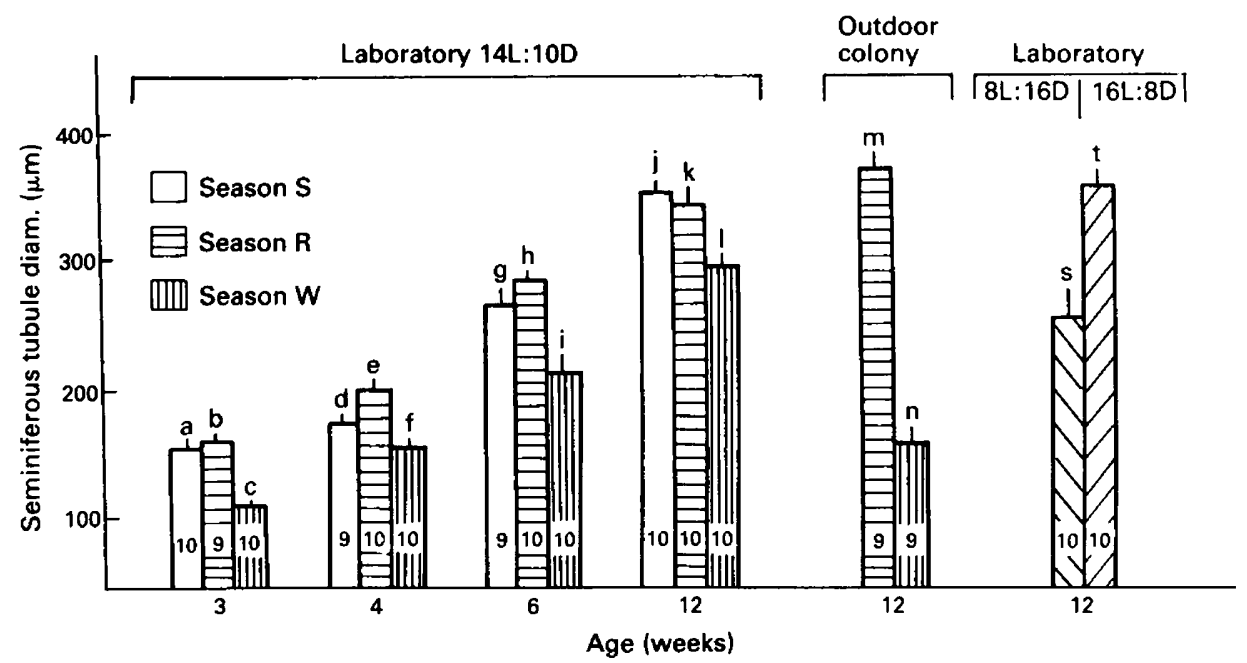

Fig. 2. Seminiferous tubule diameters of bank vole males reared in various conditions in Exps 1, 2 and 3. Values are mean \pm s.e.m. for the sample size indicated. a $v s c, b v s c, d v s$ e, $d v s, e v s f$, $\mathrm{g} v s \mathrm{i}, \mathrm{h} v s \mathrm{i}, \mathrm{j} v s \mathrm{l}, \mathrm{k} v s \mathrm{l}, \mathrm{m} v s \mathrm{n}, \mathrm{k} v s \mathrm{~m}, 1$ vs $\mathrm{n}, \mathrm{s} v s \mathrm{t}, P<0 \cdot 01$.

tubules of the voles reared in Season W (Fig. 1) were filled with Sertoli cells and spermatogonia $(S I=0)$ with sporadic primary spermatocytes $(S I=1)$, but complete spermatogenesis $(S I \geq 4)$ was found in males born in Season R. In animals from Season W smaller seminiferous tubules (Fig. 2) were found, as compared with males from Season $\mathbf{R}$.

The degree of sexual development of 12-week-old males from the laboratory colony or reared in outdoor cages (Exps 1 \& 2) was also compared. In both seasons males reared under laboratory conditions were lighter $(18.5 \pm 0.5 \mathrm{~g}, \mathrm{~N}=10$, for laboratory animals and $20.6 \pm 0.6 \mathrm{~g}, \mathrm{~N}=9$, for outdoor animals in Season $R ; 17.1 \pm 0.4 \mathrm{~g}, \mathrm{~N}=10$, for laboratory animals and $19.4 \pm 0.9 \mathrm{~g}$, $\mathrm{N}=9$, for outdoor animals in Season W. $P<0.05$ ).

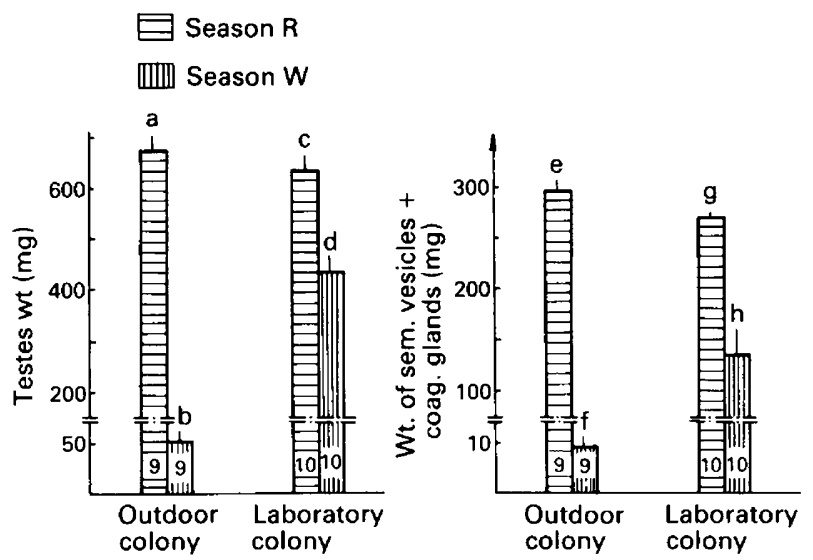

Fig. 3. Weights of testis and accessory glands in 12-week-old bank vole males reared outdoors and in the laboratory colony. Values are mean \pm s.e.m. for the sample size indicated. a $v s \mathrm{~b}, \mathrm{c}$ $v s \mathrm{~d}, \mathrm{~b} v s \mathrm{~d}, \mathrm{e} v s \mathrm{f}, \mathrm{g} v s \mathrm{~h}, \mathrm{f} v s \mathrm{~h}, P<0.01$. 
In Season $\mathrm{R}$, the testes and the seminal vesicles and coagulating glands (Fig. 3) were heavier in males reared outdoors, as compared with animals in laboratory colonies. However, these differences were not statistically significant.

In Season $\mathbf{R}$ the seminiferous tubules of the animals reared outdoors or in the laboratory were both lined with epithelium of similar activity, and the SI values were similar (Fig. 1), but the seminiferous tubule diameters (Fig. 2) of voles reared outdoors were higher.

In Season W, in 12-week-old males (Fig. 3) reared in outdoor cages, the weights of the testes and the seminal vesicles and coagulating glands were smaller than those of the animals maturing in laboratory conditions. The seminiferous tubules of males reared outdoors during winter contained Sertoli cells and spermatogonia $(S I=0)$ with sporadic primary spermatocytes $(S I=1)$, whereas in the animals from the laboratory colony spermatogenesis reached the stage of elongated spermatids $(\mathrm{SI}=3)$. The SI (Fig. 1) and the diameter of the seminiferous tubules (Fig. 2) in voles maturing outdoors in winter were smaller than those of animals reared in the laboratory in the same season.

\section{Experiment 3}

In this experiment no seasonal differences were observed, so the results obtained for males kept in the 'short' and 'long' photoperiods throughout the year were analysed jointly.

The males maturing in the short photoperiod (8L:16D) were lighter $(16.7 \pm 0.6 \mathrm{~g}, \mathrm{~N}=10)$ than those reared in the long photoperiod (16L:8D) $(19.2 \pm 0.6 \mathrm{~g}, \mathrm{~N}=10, P<0.05)$. In males reared in $8 \mathrm{~L}: 16 \mathrm{D}$, there was inhibited development of the testes, seminal vesicle and coagulating glands compared with values for the animals maturing in 16L:8D (Fig. 4).

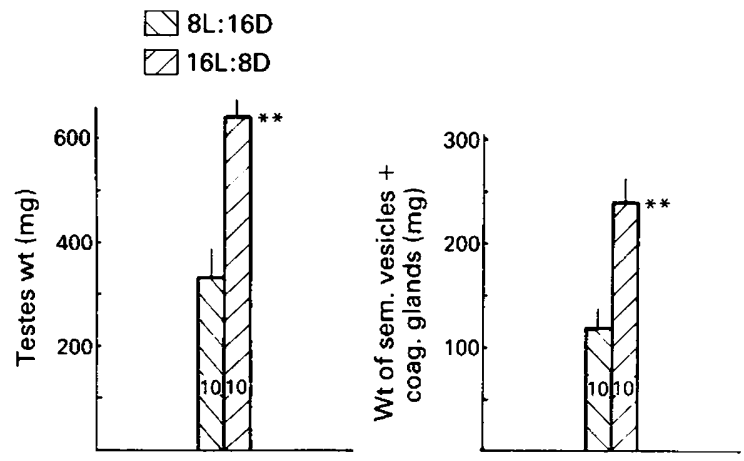

Fig. 4. Effect of short (8L:16D) and long (16L:8D) photoperiods upon the weights of testis and accessory glands in 12-week-old bank vole males. Values are mean \pm s.e.m. for the sample size indicated. ${ }^{* *} P<0.01$ compared with value for $8 \mathrm{~L}: 16 \mathrm{D}$.

In males from the $8 \mathrm{~L}: 16 \mathrm{D}$ photoperiod, spermatogenesis stopped at the stage of round or elongated spermatids ( $\mathrm{SI}=2$ or $\mathrm{SI}=3$ ), while in the bank voles reared in 16L:8D the seminiferous tubules were filled with mature spermatozoa. The SI (Fig. 1) and the diameter of seminiferous tubules (Fig. 2) of the males from $8 \mathrm{~L}: 16 \mathrm{D}$ were smaller than in voles kept in $16 \mathrm{~L}: 8 \mathrm{D}$.

\section{Discussion}

Research on the reproductive activity of wild populations of Skomer voles (Clethrionomys glareolus skomerensis) (Coutts \& Rowlands, 1969) indicates a significant influence of the season on gonadal 
function in both males and females. The reproduction period is from the beginning of March to the end of September.

The experiments now reported confirm these observations. Assuming the weights of the testes and accessory glands and the degree of morphological and functional development of the testes as the index value, it has been shown that the males reared outdoors reached maturity more slowly in winter than they do in the reproduction season. Similar seasonal differences in weight and gonadal activity were observed in male field voles (Microtus agrestis) from wild populations (Grocock \& Charlton, 1976).

Bank vole males reared in the laboratory revealed high sensitivity to the duration of the light phase of the diurnal cycle (Fig. 4). The long photoperiod accelerates spermatogenesis and induces an increase in the accessory gland weight. This has been correlated with the increase in the gonadal and adrenal gland enzymic activity described by Tähkä (1978), Tähkä, Teräväinen \& Wallgren (1982) and Tähkä, Roukonen, Wallgren \& Teräväinen (1983). In bank vole males reared in short daylength (8L:16D) conditions, a significant inhibition of sexual maturation was observed. The inhibition of maturation of the seminiferous epithelium is associated with a decrease in androgen production. Tähkä et al. (1983) showed the inhibition of androgen synthesis by the testes of bank vole males in $6 \mathrm{~L}: 18 \mathrm{D}$. Sensitivity to the length of light is characteristic of a species of the Family Microtidae; a similar effect of a short photoperiod was found to inhibit development of the reproductive system in male common voles (M. arvalis) (Lecyk, 1962; Dobrowolska \& GromadzkaOstrowska, 1983) and field voles (M. agrestis) (Clarke \& Kennedy, 1967; Grocock \& Clarke, 1974, 1975; Grocock, 1979, 1981; Craven \& Clarke, 1982). However, not all bank vole males reared in a short photoperiod responded by the underdevelopment of the reproductive system. Of the 10 males studied, 4 did not reveal any delay in sexual maturation. A similar lack of response to a short photoperiod was exhibited by male field voles (M. agrestis) (Clarke \& Kennedy, 1967). This variability is probably connected with a high heterogeneity amongst the animals investigated.

The low activity of the reproductive organs in animals reared outdoors in winter may be interpreted as a photoperiodic effect, in view of the results from the experiments with 16L:8D and 8L:16D photoperiods. Probably, as in field voles, low environmental temperatures acted as an accessory inhibitory factor (Clarke \& Kennedy, 1967).

In spite of stable laboratory conditions (warmth, long photoperiod), a significant influence of the season on the rate of sexual maturation of male bank voles was found. These seasonal effects were more striking in males reared outdoors, since they resembled the seasonal changes observed in bank voles from natural populations (Brambell \& Rowlands, 1936; Coutts \& Rowlands, 1969). A similar seasonal effect has been observed in laboratory rats. The rat males born in spring reach maturity faster than those born in autumn (Mock \& Frankel, 1978, 1980). This fact and my observations suggest that seasonality in sexual maturation is controlled by an annual, internal biological rhythm.

I thank Professor A. Marchlewska-Koj for advice and criticisms on this project and for review and helpful comments on the manuscript. This research was supported by Grant MR-II/10 from the Polish Academy of Sciences.

\section{References}

Alder, E.M. (1972) The care of the bank vole (Clethrionomys glareolus) in the laboratory. J. Inst. Anim. Tech. 26, 39-45.

Brambell, F.W.R. \& Rowlands, I.W. (1936) Reproduction in the bank vole (Evotomys glareolus, Schreber). I. The oestrous cycle of the female. Phil. Trans. $R$. Soc. Ser. B 226, 71-97.

Buchalczyk, A. (1970) Reproduction, mortality and longevity of the bank vole under laboratory conditions. Acta theriol. 15, 153-176.
Clarke, J.R. (1981) Physiological problems of seasonal breeding in eutherian mammals. In Oxford Reviews of Reproductive Biology, vol. 3, pp. 244-312. Ed. C. A. Finn. Oxford University Press.

Clarke, J.R. \& Kennedy, J.P. (1967) Effect of light and temperature upon gonadal activity in the vole, Microtus agrestis. Gen. comp. Endocr. 8, 474-488.

Coutts, P.R. \& Rowlands, I.W. (1969) The reproductive cycle of the Skomer vole (Clethrionomys glareolus skomerensis). J. Zool., Lond. 158, 1-25. 
Craven, R.P. \& Clarke, J.R. (1982) Gonadotrophin levels in male voles (Microtus agrestis) reared in long and short photoperiods. J. Reprod. Fert. 66, 709-714.

Dobrowolska, A. \& Gromadzka-Ostrowska, J. (1983) Influence of photoperiod on morphological parameters, androgen concentration, haematological indices and serum protein fractions in common vole (Microtus arvalis, Pall.). Comp. Biochem. Physiol. 74A, $427-433$.

Grocock, C.A. (1979) Testis development in the vole, Microtus agrestis, subjected to long or short photoperiods from birth. J. Reprod. Fert. 55, 423-427.

Grocock, C.A. (1981) Effects of different photoperiods on testicular weight changes in the vole, Microtus agrestis. J. Reprod. Fert. 62, 25-32.

Grocock, C.A. \& Charlton, H.M. (1976) Seasonal changes in testis activity in the vole, Microtus agrestis, 1. Light microscopic autoradiography. Gen. comp. Endocr. 29, Abstr. 108.

Grocock, C.A. \& Clarke, J.R. (1974) Photoperiod control of testis activity in the vole, Microtus agrestis. $J$. Reprod. Fert. 39, 337-347.

Grocock, C.A. \& Clarke, J.R. (1975) Spermatogenesis in mature and regressed testes of the vole, Microtus agrestis. J. Reprod. Fert. 43, 461-470.

Lecyk, M. (1962) The effects of length of daylight on reproduction in the field vole (Microtus arvalis). Zool. pol. 12, 189-221.

Mock, E.J. \& Frankel, A.J. (1978) A seasonal influence on testes weight and serum gonadotropin levels of the mature male laboratory rat. Biol. Reprod. 18, $772-778$.
Mock, E.J. \& Frankel, A.J. (1980) Influence of month of birth on the serum hormone concentrations and weights of the accessory sex organs and testes during maturation of the male laboratory rat. Biol. Reprod. 22, 119-133.

Nelson, R.J., Dark, J. \& Zucker, I. (1983) Influence of photoperiod, nutrition and water availability on reproduction of male California voles (Microtus californicus). J. Reprod. Fert. 69, 473-477.

Tähkä, K.M. (1978) A histochemical study on the effects of photoperiod on gonadal and adrenal function in the male bank vole, Clethrionomys glareolus, $J$. Reprod. Fert. 54, 57-66.

Tähkä, K.M., Teräväinen, T. \& Wallgren, H. (1982) Effects of photoperiod on testicular steroidogenesis of the bank vole (Clethrionomys glareolus): an in vitro study. Gen. comp. Endocr. 47, 337-384.

Tähkä, K.M., Roukonen, A., Wallgren, H. \& Teräväinen, T. (1983) Temporal changes in testicular histology and steroidogenesis in juvenile bank voles (Clethrionomys glareolus, Schreber) subjected to different photoperiods. Endocrinology 112, 1420-1426.

Zejda, J. (1962) Winter breeding in the bank vole (Clethrionomys glareolus Schreber). Zool. Listy 11, 309-321. 